\title{
Discussions with Leaders: A Conversation Between Sam Gambhir and Johannes Czernin
}

\author{
Johannes Czernin $^{1}$ and Sanjiv Sam Gambhir ${ }^{2}$ \\ ${ }^{I}$ David Geffen School of Medicine at UCLA, Los Angeles, California; and ${ }^{2}$ Stanford University, Stanford, California
}

$\tau$ ohannes Czernin, editor in chief of The Journal of Nuclear Medicine, recently initiated a series of recorded discussions with leaders in nuclear medicine and molecular imaging. The first of these, conducted on September 25, 2018, with Sanjiv Sam Gambhir, is excerpted below. Gambhir is the Virginia and Daniel K. Ludwig Professor of Cancer Research and chair of the Department of Radiology at the Stanford University School of Medicine. He heads the Canary Center at Stanford for Cancer Early Detection and directs the Molecular Imaging Program at Stanford, where he also directs the new Precision Health and Integrated Diagnostics Center. Gambhir's lab has focused on interrogating fundamental molecular events in living subjects. He has developed and clinically translated several multimodality molecular imaging strategies, including imaging of gene and cell therapies. An international leader in molecular imaging, he has more than 625 publications in the field, several books, and more than 40 patents pending or granted. He has received numerous federal research grants and career achievement recognitions, including, most recently, the SNMMI Benedict Cassen Prize for Molecular Imaging Research.

Dr. Czernin: You were a pioneer in the field of molecular imaging-among the first to image gene expression in vivo. At Stanford you developed a large preclinical multimodality imaging program and became deeply immersed in advancing our understanding of cancer biology. Moreover, you have led and participated in health-care policy development, health economics analyses, and cost-effectiveness research that helped secure reimbursement for PET imaging. When and how did you develop your love for and dedication to science? I understand that you graduated from high school and started college at the age of 15. When did you realize that you wanted to become a scientist?

Dr. Gambhir: Finishing high school in Tempe, AZ, at the age of 15 was quite difficult. But one teacher in particular had a profound effect on my thinking. His name was Malcolm Wells-in fact, I honored him at an event not long ago in Arizona. He was a physics teacher who had left Motorola, where he was an engineer, to teach high school students. It was not until I crossed paths with him that I became very interested in science. He had a way of explaining things that stimulated me. If it hadn't been for Wells and a few other teachers that I later encountered as a college undergraduate, I don't know if I would have developed a love for science.

Dr. Czernin: Starting college at age 15 is remarkable. How was that experience?

Dr. Gambhir: I entered Arizona State University in Tempe, where I grew up. I ended up being lucky to begin as an undergrad

COPYRIGHT @ 2018 by the Society of Nuclear Medicine and Molecular Imaging. DOI: 10.2967/jnumed.118.221648 in physics. I was too young to realistically go away for college-I still remember being teased about it. For the first couple of years my mom would drop me off on campus. It was again a terrific set of teachers who shaped my thinking. One in particular was Stuart Lindsay, who is still at Arizona State and whom I saw again just a year ago. When I was an undergraduate, he had just come from Manchester, U.K., as a new assistant professor, working on optical imaging and specifically on Raman imaging.

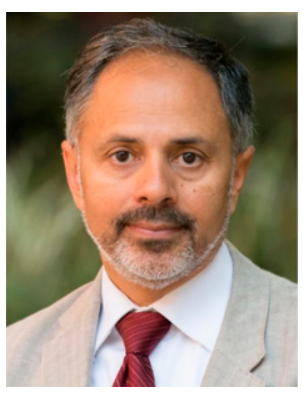

Sam Gambhir He was my first undergraduate physics teacher, along with another professor, Dr. Stoner, who trained under Albert Einstein. These two got me even more excited about physics, and my passion for science continued to build. Other individuals later contributed to my first interest in imaging. Dr. Lindsay, with whom I have stayed in touch over the years, was the one who suggested that I should expand my interests beyond physics to include biology.

Dr. Czernin: When did you develop your profound interest in the importance of translational research in really making a difference in patient outcomes? This seems, at least on the surface, to be far removed from physics.

Dr. Gambhir: That interest evolved much later. After graduating from Arizona State University, I arrived at the University of California at Los Angeles (UCLA) to begin medical school. I was just a little over 19 years old. I entered the UCLA Medical Scientists training program, in which enrollees worked on their MDs and $\mathrm{PhDs}$ concurrently over $8-10$ years. I intended to pursue physics and medicine, but this turned out to be logistically challenging. So I joined the UCLA Biomathematics Department and, again, was inspired by a wonderful teacher. Carole M. Newton, a professor of both biomathematics and radiologic sciences (who passed away in 2014), would say: "Sam, you have these mathematical skills. But what about applying them to interesting areas like imaging and other areas?" She introduced me to Sung-Cheng (Henry) Huang and Michael E. Phelps, and all the UCLA imaging experts. These two became my mentors at UCLA. With mathematics as my field, focusing on modeling came naturally. This included not only tracer kinetic modeling but also health outcomes modeling; in other words, looking at outcomes. PET imaging was still in its infancy, and its benefits needed to be demonstrated, so these kinds of outcomes studies were essential.

Dr. Czernin: When you finally did your training in nuclear medicine you were already a faculty member at UCLA. Was clinical work important to you in terms of giving you insights into 
real-life issues and unmet needs? How did clinical work stimulate your research creativity?

Dr. Gambhir: That's a good question. I was actually more interested in specializing in medicine than in nuclear medicine. But it wasn't practical to do a medicine internship and residency and still be doing research. As a result, after discussions with multiple people, including Mike Phelps, I started an internship in internal medicine and followed this up with nuclear medicine training. After my internship year, Mike asked me to join the faculty of the UCLA Department of Molecular and Medical Pharmacology. I initially did 60\% clinical work and $40 \%$ research. Of course, molecular imaging and nuclear medicine always had more physics, mathematic modeling, and biology than radiology. So molecular imaging and nuclear medicine were a good fit for me at the time, and I liked the fact that I could do clinical work. I had no intention at that time of doing less and less clinical work. But by the end of my years at UCLA I spent about $30 \%$ of my time in the clinic and $70 \%$ in research.

Dr. Czernin: You created a significant and internationally recognized program with many resources at UCLA. What was your motivation to accept another position?

Dr. Gambhir: When I was recruited to Stanford I was already a full professor at UCLA. I was vice chair of the Department of Pharmacology and headed the Crump Institute for Molecular Imaging. I was happy at UCLA. However, my wife had breast cancer, and we always thought that if her disease recurred our son Milan would do well here in the Bay Area, where we have a lot of family. I was really motivated mostly by family in our move to Stanford. Stanford was also a great opportunity. They needed a head of the Nuclear Medicine Division, which was a small section in the
Dr. Gambhir: This is certainly an important question. As a chair of a radiology department that is quite large, including 160 faculty, my views are evolving. The answer depends on each individual environment. The situation is different across institutions. Stanford is quite different from UCLA, which is quite different from the University of California at San Francisco or Johns Hopkins. At Stanford it makes sense to have everything integrated into a single department, in part because the culture here is somewhat different in radiology. One third of our faculty members are basic scientists. If a radiology department is heavily focused on clinical activity and not so much on research, then priorities will be different.

Dr. Czernin: That's unusual, because radiology is often not that academically driven. It's instrumentation- and anatomy- much more than biology-driven. But even if radiology at certain sites has a strong academic program, why would a merger be helpful?

Dr. Gambhir: In the few universities that I know of with very strong scientific infrastructures in radiology it makes a lot of sense to merge departments. Stanford is not the only place like that. The University of Pennsylvania is another institution in which the Department of Radiology also includes fundamentally good science. This is the case at Massachusetts General Hospital, Johns Hopkins, the University of California at San Francisco, and others. If you ask where nuclear medicine belongs in such places it is clear that it integrates well with radiology. Nuclear medicine and molecular imaging fit well with the rest of radiology, for example, when you consider research into hyperpolarized MRI. Here at Stanford, we want to go further by combining the Department of Radiology, which already includes nuclear medicine, with the Department of Pathology. We're moving toward a model where the 2 departments will likely merge completely over the course of

\section{"We shouldn't be celebrating how full our hospitals are. We should celebrate when our hospitals are empty!"}

Department of Radiology. They also needed help in building a molecular imaging program so that people in multiple departments across the university could access preclinical molecular imaging resources and begin to appreciate the ways in which these resources could advance their scientific work. When first at Stanford, I spent nearly $80 \%$ of my time in the clinic, because we had only 2 additional attendings in nuclear medicine. I headed the division for 8 years, recruiting other faculty over time to build the clinic. At the same time, I started focusing on building the research program.

Dr. Czernin: Before we talk about your research we should talk a little bit about politics. You are a trained nuclear medicine physician who now chairs a leading radiology department. I am a strong proponent of independence and equidistance among many clinical disciplines. This implies that nuclear medicine should stand on its own at the intersect between various independent clinical disciplines, including medicine, endocrinology, radiation oncology, cardiology, neurology, and, of course, radiology. Such independence has led to extraordinarily strong programs in Europe, Australia, and Asia. In the United States, nuclear medicine has been part of radiology for decades-in other words, it has lacked independence. With the emergence of theranostics it is evident that training requirements will have to change and that the role of nuclear medicine will change. What should the relationship between nuclear medicine and radiology look like? a decade. In fact, we want to find a single replacement for the chairs of radiology and pathology to create the next generation of diagnosticians. We could see interesting molecular imaging opportunities when combined with pathology. Pathology departments, of course, have significant fundamental basic science research programs.

Dr. Czernin: I believe we must empower individuals and allow them to develop a sense of ownership. It requires wise leadership to accomplish this in academia. I don't think that this is any easier when everyone is under the same administrative umbrella. Power struggles, territorial issues, and preference-driven financial priorities all come into play. I often think that a bottom-up flow of ideas is much better than top-down administration. Central administrations can suffocate innovation and research. Bottom line: freedom is critically important because it fosters creativity. Another issue is financial independence. It's difficult for nuclear medicine to remain economically viable. For example, relative value units are not a measure that can be applied in nuclear medicine. Yet in Europe and Asia, PET/CT is financially viable and is an integral part of nuclear medicine. Theranostics will be financially viable.

Dr. Gambhir: I run things very quantitatively in our department at Stanford. Each division has metrics. I look at overall relative value units generated by each division, as well as other 
measures of productivity beyond that. We look at divisional revenues, where we use a 75th percentile metric. If a division begins to exceed the 75th percentile of national reference data, we hire more people. If a division is not performing, it is overstaffed. We tend to look at all this quantitatively—not just assessing clinical productivity. We also look at federal grant funding, industry support, etc., so that a division is evaluated holistically. Our department is now usually ranked second or third in the country in overall National Institutes of Health funding. What I'm rambling on about here is that each academic medical center is a unique entity. Stanford methods and metrics may not apply elsewhere. I think it's better for nuclear medicine to be part of a larger system. In addition, I don't think that theranostics is really the big opportunity that will make a huge difference for nuclear medicine. Yes, it's a major shortterm opportunity. But our victories will not come from therapies. They will come from earlier disease detection. If I were to put longterm bets for our field, I would see a future that focuses on achievements in catching disease much earlier than we do now-so that these complex therapies are not needed to begin with. That's why I see the link to pathology as crucial and in vitro diagnostics as even more critical than theranostics.

Dr. Czernin: This brings me to the translatability of diagnostic approaches. At the 2016 World Molecular Imaging Conference in New York, NY, there seemed to be a fairly subdued and somber mood about what has been translated successfully into the clinic. What has happened, and what has not happened? Was molecular imaging a hype? What do you see as the key translational success of molecular imaging?

Dr. Gambhir: As with everything in science, we always underestimate the timespan required to result in real-world impacts. Look at PET, which took so much longer than anyone anticipated. In fact, if you'd asked 15 years ago I would have predicted that we would have many more tracers in the clinic. I just came back from the 2018 World Molecular Imaging Congress in Seattle, WA. One of the most rapidly growing areas is intraoperative molecular imaging using optical approaches. Could we have predicted that 15 years ago? We already had evidence of optical imaging agents being useful, even in the surgical context. We're now seeing more and bigger reports about the utility of these approaches in clinical settings. The burden is showing that interoperative applications of molecular imaging actually improve outcomes. If you remove that tumor that you would have missed without fluorescence guidance, does this really affect outcomes? These translations take longer than we think. We could still be talking about this a decade from now. What helps translatability, especially where surgery is involved, is acceptance by surgeons. We have another conference, the Imaging in 2020 meeting, which takes place in Jackson Hole, WY, every year. It is attended by both surgeons and molecular imaging specialists from around the world. The advantages of surgeons understanding and buying into molecular imaging are significant. Some people say, "Well, molecular imaging with these or other modalities doesn't seem to be going anywhere." Quite the opposite. It is translating. And it's going to make an impact in clinical settings.

Dr. Czernin: Sam, what are your goals in research and outcomes for the next 10 years? You talked already about early detection, which, of course, is really important. What drives you now, and where do you see the greatest potential impact?

Dr. Gambhir: First is the concept of organizing ideas from the university level down to the medical school level. We just went through a long strategic planning process that will decide the fate of Stanford for the next 20 years. We have a new president, Marc Tessier-Lavigne, who is a neuroscientist himself and was president of The Rockefeller University and executive vice president for research and chief scientific officer at Genentech, Inc. He has gone through a process over the last year and a half of long-term strategic planning for the entire university. I've been pushing for what we call "precision health." This is different from what is usually discussed as precision medicine. Theranostics, for example, would be a focus of precision medicine. We talk about precision health because we believe the big opportunities in health care go beyond simply developing new drugs. Many of the big wins will come from the science and understanding of transitions from health to illness. We're concentrating on research in the basic biology of transitions from normal to early disease at the cellular and molecular levels. Technologies need to be developed for early detection of these transitions. The general focus in our field and others seems to be to continue to look at late-stage disease-often too late. Why are men with prostate cancer and advanced metastatic disease even getting to that stage to begin with? I think a lot of the world continues to focus on the wrong end of the problem. Of course, we should continue to identify and help individuals in latestage disease. But we shouldn't be celebrating how full our hospitals are. We should celebrate when our hospitals are empty! The health-care system should be celebrating keeping people healthy. The metrics will change so that we get paid not for how much we treat but for how well we take care of a population. How do we look for newer ways to detect disease early when we can't prevent it? My research efforts are fully in this area. We are doubling down on what we believe will pay off not in 5 or 10 years but in 20 years, when I don't think we'll be talking about how we treat. Instead, I hope we'll be talking about how we have very few people who progress to the need for late-stage treatment because so many technologies and approaches are available to address disease earlier.

Dr. Czernin: Sam, I've really enjoyed talking to you about these issues and am sure our readers will like this too. Thank you very much for your time. 